\title{
CORRESPONDENCE
}

\section{Rethinking the respiratory paradigm of COVID-19: a 'hole' in the argument}

\author{
Rajkumar Rajendram ${ }^{1,3,4^{*}}$ (D), Ghulam Abbas Kharal ${ }^{5}$, Naveed Mahmood ${ }^{1,2,3}$, Rishi Puri6 and Mubashar Kharal ${ }^{1,3}$
}

(c) 2020 Springer-Verlag GmbH Germany, part of Springer Nature

\section{Dear Editor,}

The number of admissions was more than the hospital had ever seen. Patients were dying of respiratory failure. Doctors and nurses were unable to cope. At Blegdam Hospital, Copenhagen in 1952, Bjørn Ibsen's use of invasive positive pressure ventilation, then revolutionary, saved countless lives from polio and initiated the development of intensive care units (ICUs) [1].

In 2020, ICUs around the world are flooded with coronavirus disease 2019 (COVID-19). The response to this pandemic has focused on increasing availability of intensivists, ICU beds, and ventilators. So, in keeping with Maslow's law of the hammer, these patients are generally being treated as if they have acute respiratory distress syndrome (ARDS).

However, the 'ARDS' caused by COVID-19 is atypical $[2,3]$. We therefore read the editorial written by Gattinoni et al. [2] with great interest. They describe two distinct patterns of respiratory COVID-19 (type L, low elastance and type $\mathrm{H}$, high elastance) [2]. However, there is a 'hole' in their argument. A series of patients with COVID-19, also described by Gattinoni's group; had a mean shunt fraction of $0.50 \pm 0.11$ despite relatively preserved pulmonary compliance $\left(50.2 \pm 14.3 \mathrm{ml} / \mathrm{cmH}_{2} \mathrm{O}\right)$ [3].

The cause of this shunt is likely to be multifactorial. Further consideration of its aetiology may be important. Right-to-left (RTL) shunt may be extrapulmonary (EPS) and/or intrapulmonary (IPS). A degree of IPS is

\footnotetext{
*Correspondence: rajkumarrajendram@doctors.org.uk

${ }^{1}$ Department of Medicine, King Abdulaziz Medical City, King Abdulaziz International Medical Research Center, Ministry of National Guard - Health Affairs, Riyadh, Saudi Arabia

Full author information is available at the end of the article
}

inevitable. However, EPS may be present in some patients with COVID-19.

Extrapulmonary shunt is often intracardiac (ICS) [4]. Echocardiography with bubble contrast, a minimally invasive bedside test, can be used to detect ICS [4]. This is most commonly due to patent foramen ovale (PFO) [4]. Hypoxia is an uncommon complication of PFO unless a precipitant such as COVID-19 initiates RTLICS. However, because the prevalence of PFO in the general population is $20-30 \%$, EPS may be relevant to many patients with COVID-19 worldwide.

We therefore suggest that respiratory failure should be classified into four dynamic phenotypes based on total shunt (i.e. IPS $\pm E P S$ ) and lung mechanics:

Type L respiratory failure

- due to IPS alone (Subtype LPS)

- due to IPS and EPS (Subtype LES)

Type $\mathrm{H}$ respiratory failure

- due to IPS alone (Subtype HPS)

- due to IPS and EPS (Subtype HES)

Worsening pulmonary pathology progresses from Type $\mathrm{L}$ to $\mathrm{H}$. Increasing airway pressures could induce HES [5]. There are few data to guide management of patients with EPS. However, the standard approach to refractory hypoxia may exacerbate RTLICS whilst trying to reduce IPS [5]. The patients with RTLICS respond poorly to positive end expiratory pressure are ventilated longer, and stay longer in ICU [5]. Reducing airway pressures may allow reversion to HPS. As the lung injury resolves, both total shunt and lung mechanics may normalise. 
Use of this paradigm could help refining the management of respiratory failure and refractory hypoxia. Observations in COVID-19 may be relevant to other respiratory diseases. However, future trials should explore the impact of specific treatments for EPS (e.g. PFO closure) on outcomes.

\section{Author details}

1 Department of Medicine, King Abdulaziz Medical City, King Abdulaziz International Medical Research Center, Ministry of National Guard - Health Affairs, Riyadh, Saudi Arabia. ${ }^{2}$ Department of Cardiology, King Abdulaziz Medical City, King Abdulaziz International Medical Research Center, Ministry of National Guard - Health Affairs, Riyadh, Saudi Arabia. ${ }^{3}$ College of Medicine, King Saud bin Abdulaziz University of Health Sciences, Riyadh, Saudi Arabia. ${ }^{4}$ Department of Anaesthesia and Intensive Care, Stoke Mandeville Hospital, Aylesbury, Buckinghamshire, UK. ${ }^{5}$ Division of Cerebrovascular Disorders, Cleveland Clinic Neurological Institute, Cleveland Clinic Foundation, Cleveland, $\mathrm{OH}$ USA. ${ }^{6}$ Department of Cardiovascular Medicine, Heart and Vascular Medicine Institute, Cleveland Clinic Foundation, Cleveland, OH, USA.

\section{Funding}

None.

\section{Compliance with ethical standards}

\section{Conflicts of interest}

On behalf of all authors, the corresponding author states that there is no conflict of interest.

\section{Publisher's Note}

Springer Nature remains neutral with regard to jurisdictional claims in published maps and institutional affiliations.

Accepted: 9 May 2020

Published online: 2 June 2020

\section{References}

1. Wunsch H (2020) The outbreak that invented intensive care. Nature. https //doi.org/10.1038/d41586-020-01019-y

2. Gattinoni L, Chiumello D, Caironi P, Busana M, Romitti F, Brazzi L, Camporota L (2020) COVID-19 pneumonia: different respiratory treatment for different phenotypes? 2020. Intensive Care Med. https://doi.org/10.1007/ s00134-020-06033-2

3. Gattinoni L, Coppola S, Cressoni M, Busana M, Rossi S, Chiumello D (2020) Covid-19 does not lead to a "typical" acute respiratory distress syndrome. Am J Respir Crit Care Med. https://doi.org/10.1164/rccm.202003-0817LE

4. Agrawal A, Palkar A, Talwar A (2017) The multiple dimensions of Platypnea-Orthodeoxia syndrome: a review. Respir Med 129:31-38

5. Vavlitou A, Minas G, Zannetos S, Kyprianou T, Tsagourias M, Matamis D (2016) Hemodynamic and respiratory factors that influence the opening of patent foramen ovale in mechanically ventilated patients. Hippokratia 20:209-213 